Abstract S107 Table 1

\begin{tabular}{llll}
\hline & Control $(\mathbf{n}=\mathbf{5})$ & High-stretch $(\mathbf{n}=\mathbf{3})$ & Atelectasis $(\mathbf{n}=\mathbf{5})$ \\
\hline $\begin{array}{l}\text { Protein in lavage fluid } \\
\text { (mg/ml) }\end{array}$ & $0.21 \pm 0.04$ & $4.07 \pm 2.21^{*}$ & $4.81 \pm 1.67^{*}$ \\
$\begin{array}{l}\text { Perfusate chemokines } \\
\text { MIP-2 (ng/ml) }\end{array}$ & $1.12 \pm 0.70$ & $4.29 \pm 0.82^{*} \dagger$ & $1.48 \pm 0.67$ \\
KC (ng/ml) & $1.26 \pm 0.74$ & $6.71 \pm 1.79^{*} \dagger$ & $1.70 \pm 1.09$ \\
Lavage fluid chemokines & & & \\
MIP-2 (ng/ml) & $0.13 \pm 0.06$ & $4.39 \pm 1.98^{*} \dagger$ & $0.69 \pm 0.26^{*}$ \\
KC (ng/ml) & $0.12 \pm 0.04$ & $5.15 \pm 1.42^{*} \dagger$ & $0.82 \pm 0.47^{*}$ \\
\hline
\end{tabular}

${ }^{*} \mathrm{p}<0.05$ versus control.

$t p<0.05$ versus atelectasis.

MIP-2, Macrophage-inflammatory protein-2; KC, Kerationocyte-derived chemokine.

Conclusion While both high-stretch and atelectasis can induce barrier dysfunction, only high-stretch induced substantial production of chemokines by the lung and their release into the circulation. These findings suggest that over distension of the lung, rather than collapse/reopening associated with atelectasis, primarily contributes to the exacerbated pulmonary and systemic inflammation during VILI. Our results may provide insights into why addition of PEEP to limit atelectasis has limited clinical outcome benefit in ventilated patients with acute lung injury.

\section{Epidemiology of lung disease S108 A HISTORICAL COHORT STUDY TO DETERMINE THE PREVALENCE OF COMMON CHRONIC RESPIRATORY DISEASES AND MEDICATION USE IN DRUG MISUSERS}

doi:10.1136/thx.2010.150946.9

F Palmer, M Jaffray, M Moffat, C Matheson, J Haughney, A Coutts. University of Aberdeen, Aberdeen, Scotland

Introduction and aim A local substance misuse study and anecdotal evidence from primary care, suggested many methadone patients have respiratory disease and/or prescriptions for respiratory preparations. Anecdotal evidence from clinical colleagues supports this. With little published literature in this area, this preliminary study aimed to explore the prevalence of respiratory diseases and prescriptions for respiratory medication in drug misusers.

Method This exploratory study used a historical cohort design with matched controls. An analysis of Primary Care Clinical Informatics Unit (PCCIU) GP consultation data was conducted. The prevalence of common respiratory diseases (ever appearing in the patient's medical records) and commonly used respiratory prescriptions (in 2008) between drug misusers and matched controls (general population sample) was compared.

Results The PCCIU data contained a cohort of 18570 patients (9285 per group), of which, $64 \%(n=11885)$ were male and $75.7 \%$ $(n=14060)$ were aged $31-59$. Results revealed an increased prevalence of chronic respiratory disease in drug misusers versus controls. Drug misusers were more likely to be prescribed chronic respiratory diseases medications than controls. These results were still significant when adjusted for smoking status, where those who had never smoked were compared to those who had ever smoked (current and ex smokers) (See Abstract S108 Table 1). Median quantity of SABA and ICS prescriptions during 2008 were also statistically significantly higher in drug misusers*. The median quantity of SABA prescribed for drug misusers were 4 (IOR 2-8) vs 3 (IOR 1-7) in controls**. The median quantity of ICS prescribed for drug misusers were 4 (IOR 2-8) vs 2 (IOR 1-5) in controls**. *Median Prescription for patients on $\geq 1$ prescription. ${ }^{* *} \mathrm{p}<0.001$ Mann-Whitney U.
Abstract S108 Table 1 Comparisons using PCCIU SPICE data

\begin{tabular}{|c|c|c|c|c|}
\hline & Drug misusers & Controls & $\begin{array}{l}\text { Crude OR } \\
(95 \% \mathrm{Cl})\end{array}$ & $\begin{array}{l}\text { Adjusted OR } \\
\text { (95\% CI) }\end{array}$ \\
\hline Asthma diagnosis & $1590(17.1 \%) \dagger$ & $1009(10.9 \%) \dagger$ & $\begin{array}{l}1.695(1.557 \\
\text { to } 1.845) \neq\end{array}$ & $\begin{array}{l}1.633(1.485 \\
\text { to } 1.796) \ddagger\end{array}$ \\
\hline $\begin{array}{l}\text { COPD (chronic } \\
\text { obstructive } \\
\text { pulmonary disease) } \\
\text { diagnosis }\end{array}$ & $219(2.4 \%) \dagger$ & $74(0.8 \%) \dagger$ & $\begin{array}{l}3.007(2.307 \\
\text { to } 3.920) \neq\end{array}$ & $\begin{array}{l}1.752(1.336 \\
\text { to } 2.297) \neq\end{array}$ \\
\hline $\begin{array}{l}\text { SABA (short acting } \\
\beta \text { agonist) } \\
\text { prescribed* }^{*}\end{array}$ & $1520(16.4 \%) \dagger$ & $736(7.9 \%) \dagger$ & $\begin{array}{l}2.274(2.071 \\
\text { to } 2.496) \neq\end{array}$ & $\begin{array}{l}1.998(1.803 \\
\text { to } 2.214) \neq\end{array}$ \\
\hline $\begin{array}{l}\text { LABA (long acting } \\
\beta \text { agonist) } \\
\text { prescribed }^{*}\end{array}$ & $92(1 \%) \dagger$ & $39(0.4 \%) \dagger$ & $\begin{array}{l}2.373(1.630 \\
\text { to } 3.454) \ddagger\end{array}$ & $\begin{array}{l}1.883(1.255 \\
\text { to } 2.825) \neq\end{array}$ \\
\hline $\begin{array}{l}\text { ICS (inhaled } \\
\text { corticosteroid) } \\
\text { prescribed }^{*}\end{array}$ & $987(10.6 \%) \dagger$ & $702(7.6 \%) \dagger$ & $\begin{array}{l}1.454(1.314 \\
\text { to } 1.609) \ddagger\end{array}$ & $\begin{array}{l}1.500(1.339 \\
\text { to } 1.681) \neq\end{array}$ \\
\hline
\end{tabular}

Conclusion These data suggest, drug misusers have a significantly higher prevalence of respiratory diseases and are prescribed significantly more respiratory medications than matched controls. Adjusting for smoking status, still revealed drug misusers have significantly increased odds of have a respiratory disease or being prescribed respiratory medication, indicating there may be more complex factors involved related to drug use needing further exploration. As a first stage exploratory study, we have set the scene for future work to begin to determine the potential reasons for this association.

\section{S109 CURRENT COPD CARE IN THE UK; RESULTS FROM 180000 PATIENTS IN THE POINTS DATABASE}

doi:10.1136/thx.2010.150946.10

${ }^{1}$ A De Soyza, ${ }^{2} \mathrm{~J}$ Roberts. ${ }^{1}$ Newcastle University /Freeman Hospital, Newcastle upon Tyne, UK; ${ }^{2}$ Salford Royal Hospital NHS Foundation Trust and NHS Salford, Salford, UK

Background COPD is a major healthcare burden in the UK with one million diagnosed patients. Despite a number of evidence-based guidelines, managing COPD is not straightforward. Differing standards of care exist; those qualifying for Quality \& Outcomes Framework QOF versus Non-incentivised NICE guidelines.

Aims To define a large UK wide COPD cohort and describe their current care as recorded in primary care databases.

Methods We interrogated the POINTS ${ }^{1}$ database of all participating practises in the UK. Data were collected between 2007and 2009.

Results 1406 GP Practices participated with total list size $\sim 7.9$ million of these $\sim 180000$ COPD patients were listed. 1009 practices returned list sizes giving approximately $1.8 \%$ prevalence of COPD. Approx 45000 (25\%) were current smokers of these 31000 (69\% of smokers) had received recent smoking cessation education $30 \%$ were of working age ( $<65$ years). 96000 (50\%) had a $\mathrm{FEV}_{1}$ recorded within 12 months, 147000 had flu and/or pneumococcal vaccination status recorded (80\%). Only 15\% (27500) had exacerbation frequency recorded. Progressive increases in MRC dyspnoea score (MRCD) recording occurred each year from 2007 at $29 \%$ to $44 \%$ in 2009. The most common prescription was short acting $\beta$ agonist SABA in $66 \%$, Inhaled corticosteroid/Long acting $\beta$ agonist (ICS/LABA) combination inhaler in $47 \%$, LAMA (long acting muscarinic antagonist) in 30\%. We noted $27514(15 \%)$ were prescribed an ICS inhaler which is out of licence and against NICE guidelines. $6 \%$ were prescribed a mucolytic.

Conclusions This cohort is one of the largest reported. Certain limitations may apply: possible non-random participation of practises, incorrect COPD diagnosis and incomplete datasets. Despite exacerbation rate reduction being a key management goal, 
exacerbations are poorly recorded suggesting COPD reviews are poorly conducted/documented. This may lead to failure to increase maintenance regimens. Longitudinal assessment noted rapid increase in MRCD recording after this became remunerable under QOF. Exacerbation frequency recording should be incorporated into QOF. This dataset sets a baseline from which effectiveness of the National Clinical Strategy can be measured.

${ }^{1}$ The Patient Outcomes \& Information Service (POINTS) is provided by GlaxoSmithKline as a service to medicine and is delivered on behalf of GlaxoSmithKline by Quintiles.

\section{S110 EMPLOYMENT HISTORIES OF PEOPLE WITH ASTHMA IN THE 1958 BIRTH COHORT}

doi:10.1136/thx.2010.150946.11

${ }^{1} \mathrm{R}$ Ghosh, ${ }^{1} \mathrm{D}$ Jarvis, ${ }^{2} \mathrm{D}$ Strachan, ${ }^{1} \mathrm{P}$ Cullinan. ${ }^{1} / \mathrm{mperial}$ College, London, UK; ${ }^{2}$ St. Georges, University of London, London, UK

Reports suggest that people with asthma experience frequent job changes, perhaps to avoid working environments that worsen their asthma. The aim of this analysis is to compare the number of periods of unemployment and jobs from early to mid adult life in people with and without asthma. Due to the differing employment histories of men and women the analyses are presented stratified by sex.

Methods Participants from the 1958 birth cohort who provided a full occupational history and information on asthma at ages 16 and 42 $(n=9856)$ were included. Employment was defined as a period spent in a job, in child/family care or in full-time education. Unemployment was defined as a period out of employment due to unemployment, sickness/disability or other unspecified reasons. Non-parametric methods were used to determine differences in (1) ever being unemployed (2) number of unemployment periods and (3) number of jobs (all to the age of 42 years) by asthma status (childhood asthma, adult onset asthma and the reporting of 'ever asthma' at age 42).

Results $45.8 \%$ of men and $39.5 \%$ of women had ever been unemployed by age 42 . The median number of jobs by age 42 was 6 (range $1-23$ ) and of unemployment periods was 0 (range $0-15$ ).

1. In women, adult onset asthma and reporting 'ever asthma' at 42 were significantly associated with ever being unemployed ( $p=0.026, p<0.000$ respectively), but no associations were seen in men.

2. Childhood asthma and reporting 'ever asthma' at 42 were not associated with the number of unemployment periods in either men or women. However, adult onset asthma was associated with increased number of unemployment periods in women $(p=0.033)$, but not men.

3. Differences in number of jobs by asthma status are tabulated. Conclusions In a cohort of adults born in 1958, women with adult onset asthma had an increased risk of experiencing unemployment, an increased number of unemployment periods and an increased number of jobs by age 42 years. In men, there was limited evidence that their asthma influenced their employment experience. It is not known whether these associations are seen in more recent cohorts.

\begin{tabular}{|c|c|c|c|c|c|c|}
\hline Median number of: & $\mathbf{n}$ & $\begin{array}{l}\text { Jobs MEN } \\
\text { (IOR) }\end{array}$ & $\begin{array}{l}\text { p Value } \\
\text { (Mann- } \\
\text { Whitney) }\end{array}$ & $\mathbf{n}$ & $\begin{array}{l}\text { Jobs } \\
\text { WOMEN } \\
\text { (IOR) }\end{array}$ & $\begin{array}{l}\text { p Value } \\
\text { (Mann- } \\
\text { Whitney) }\end{array}$ \\
\hline Childhood asthma NO & 2972 & 5 (3 to 7$)$ & $p=0.310$ & 3436 & 6 (4 to 9 ) & $p=0.513$ \\
\hline Childhood asthma YES & 487 & $5(3$ to 7$)$ & & 352 & 6 (4 to 9 ) & \\
\hline Adult onset asthma NO & 3549 & 5 (3 to 7$)$ & $\mathrm{p}=0.583$ & 3852 & 6 (4 to 9 ) & $p=0.005$ \\
\hline Adult onset asthma YES & 250 & 5 (3 to 8$)$ & & 424 & 7 (4 to 9 ) & \\
\hline Ever asthma by $42 \mathrm{NO}$ & 4248 & 5 (3 to 7$)$ & $p=0.029$ & 4469 & 6 (4 to 9 ) & $p<0.000$ \\
\hline Ever asthma by 42 YES & 480 & 5 (3 to 8$)$ & & 623 & 7 (4 to 9 ) & \\
\hline
\end{tabular}

Funding This work was funded by Asthma UK, RG PhD funded by the COLT Foundation. S111 ASTHMA, PUBERTY AND BMI IN THE 1958 BRITISH BIRTH
COHORT

doi:10.1136/thx.2010.150946.12

D L Jarvis, L Gnatiuc, R B Newson. Imperial College London, London, UK

Studies suggest asthma is associated with body mass index (BMI), pubertal development and hormonal status. We used data collected at ages 7, 11, 16 and 33 from the 1958 British Birth Cohort to explore the association of asthma with BMI and pubertal development. Wheeze was considered present at age 7,11 or 16 if participant's mothers reported 'ever attacks of asthma or wheezy bronchitis' and, at age 33, if participants reported 'wheezing or whistling in the chest' in the last year. Age of menarche was reported at age 16 . The association at each age of wheeze with BMI $(<18.5,18.5<25,25+)$ and with age of menarche $(<12,13-14$ years, $16+)$ was assessed in logistic regression models adjusted for parental asthma, father's social class, birth order and smoking (age 33 only). At age 7, 11 and 16, being overweight was associated with wheeze, an association that was stronger and more significant in girls than in boys. Wheeze at age 33 was associated with being overweight at age 33 in both men and women, but there was no consistent evidence that being overweight in childhood was associated with wheeze at the age of 33. Among 4524 girls with information $15.4 \%$ had reached menarche by age 12 , and $2.2 \%$ had not reached menarche by age 16 . The prevalence of being overweight at age 11 in the early and late menarche groups was $20.6 \%$ and $1.25 \%$ respectively, and the prevalence of being underweight at the age of 16 was $3.7 \%$ and $47.0 \%$. Early menarche was associated with wheeze at age 11 ( $\mathrm{OR}=1.57,95 \% \mathrm{CI} 1.19$ to 2.09$)$ even in 11-year-old girls with normal BMI. Late, but not early menarche was associated with wheeze at age $16(\mathrm{OR}=2.09,95 \% \mathrm{CI} 1.17$ to 3.73$)$. Neither early nor late menarche was associated with wheeze at age 33 years. At each follow-up of the 1958 birth cohort, wheeze was associated with being overweight in females. Although girls with early menarche were more overweight in childhood, and experienced more wheeze at age 11 , there was no evidence that early menarche was associated with wheeze at the age of 33 years.

\section{S112 THE NATURAL HISTORY OF WHEEZE FROM BIRTH TO ADULT LIFE: A COHORT STUDY}

doi:10.1136/thx.2010.150946.13

${ }^{1} \mathrm{M} L$ Burr, ${ }^{1} \mathrm{~F} \mathrm{D}$ J Dunstan, ${ }^{2} \mathrm{~S}$ Hand, ${ }^{3} \mathrm{~K}$ P Jones, ${ }^{3} \mathrm{~S}$ Rolf. ${ }^{1}$ Cardiff University, Cardiff, UK; ${ }^{2}$ Prince Charles Hospital, Merthyr Tydfil, UK; ${ }^{3}$ UWIC, Cardiff, UK

Introduction and objectives Wheeze is a common symptom at all ages. Its natural history from birth to adulthood was studied in a birth cohort of individuals at high risk of atopic illness. The objective was to ascertain factors associated with wheeze at different ages, distinguishing between wheeze that occurred at successive time points (persistent wheeze) and wheeze newly occurring (incident wheeze). Methods 497 infants were selected antenatally as having a firstdegree relative with a history of asthma, hay fever or eczema. During their first year and at 7 years the children were examined, symptoms were recorded, skin prick tests performed and serum $\operatorname{IgE}$ measured. At 15 and 23 years further questionnaires were completed and (at 23) blood and skin tests performed.

Results Information was obtained on 483 individuals at 1 year, 453 at seven, 363 at 15 and 304 at 23. The prevalence of wheeze was fairly constant over time (around $30 \%$ ), remission being balanced by incidence over each interval. Wheeze at 1 year predicted wheeze at ages seven and 15 , and at seven it predicted wheeze at 15 and 23 , but it was associated with different factors at different times and according to whether it was persistent or incident. In infancy it was related to non-atopic factors such as infection, maternal smoking and breastfeeding (protective). Persistent wheeze to age 15 was 